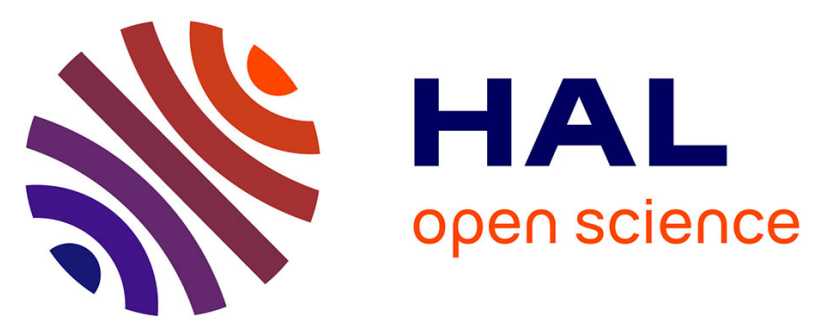

\title{
The impact of aircraft noise exposure on objective parameters of sleep quality: Results of the DEBATS study in France
}

Ali Mohamed Nassur, Damien Leger, Marie Lefevre, Maxime Elbaz, Fanny

Mietlicki, Philippe Nguyen, Carlos Ribeiro, Matthieu Sineau, Bernard

Laumon, Anne-Sophie Evrard

\section{To cite this version:}

Ali Mohamed Nassur, Damien Leger, Marie Lefevre, Maxime Elbaz, Fanny Mietlicki, et al.. The impact of aircraft noise exposure on objective parameters of sleep quality: Results of the DEBATS study in France. Sleep Medicine, 2019, 54, pp. 70-77. 10.1016/j.sleep.2018.10.013 . hal-01980952v2

\section{HAL Id: hal-01980952 \\ https://hal.science/hal-01980952v2}

Submitted on 17 Jun 2019

HAL is a multi-disciplinary open access archive for the deposit and dissemination of scientific research documents, whether they are published or not. The documents may come from teaching and research institutions in France or abroad, or from public or private research centers.
L'archive ouverte pluridisciplinaire HAL, est destinée au dépôt et à la diffusion de documents scientifiques de niveau recherche, publiés ou non, émanant des établissements d'enseignement et de recherche français ou étrangers, des laboratoires publics ou privés. 
Title: The impact of aircraft noise exposure on objective parameters of sleep quality: Results of the DEBATS study in France

\section{Authors:}

Ali-Mohamed NASSUR ${ }^{1}$, Damien LÉGER ${ }^{2}$, Marie LEFÈVRE ${ }^{1}$, Maxime ELBAZ ${ }^{2}$, Fanny MIETLICKI ${ }^{3}$, Philippe NGUYEN ${ }^{3}$, Carlos RIBEIRO ${ }^{3}$, Matthieu SINEAU ${ }^{3}$, Bernard LAUMON $^{4}$, Anne-Sophie EVRARD ${ }^{1}$

\section{Author affiliations:}

${ }^{1}$ Univ Lyon, Université Claude Bernard Lyon1, IFSTTAR, UMRESTTE, UMR T_9405, Bron, France

${ }^{2}$ Université Paris Descartes, APHP, Hôtel-Dieu de Paris, Centre du Sommeil et de la Vigilance et EA 7330 VIFASOM, Paris, France

${ }^{3}$ Bruitparif, Noise Observatory in Ile de France, Paris, France

${ }^{4}$ IFSTTAR, Transport, Health and Safety Department, Bron, France 


\section{Correspondence to:}

Anne-Sophie Evrard

IFSTTAR

Cité des Mobilités, 25 Avenue François Mitterrand, F-69675, Bron, France

Tel.: 0033472142463

Fax: 0033472376837

anne-sophie.evrard@ifsttar.fr 


\begin{abstract}
Background: Noise in the vicinity of airports is a crucial public health issue. Exposure to aircraft noise has been shown to have adverse effects on health and particularly on sleep. Many studies support the hypothesis that noise at night can affect subjective sleep quality. Fewer studies, however, have performed objective measurements of sleep.
\end{abstract}

Objectives: The aim of the present study was to investigate the relationship between aircraft noise exposure and objective parameters assessed by actigraphy of sleep quality in the population living near two French airports.

Methods: This study includes 112 participants living in the vicinity of Paris-Charles de Gaulle and Toulouse-Blagnac airports. Wrist actigraphy measurements were performed during eight nights to evaluate objective parameters of sleep quality such as sleep onset latency (SOL), wake after sleep onset (WASO), total sleep time (TST), time in bed (TB) and sleep efficiency (SE). Acoustic measurements were made simultaneously both inside the participants' bedrooms and outside (at the exterior frontage) in order to estimate aircraft noise levels. Energy indicators related to the sound energetic average for a given period of time, as well as indicators related to noise events (such as the number of events that exceed a given threshold for example) were estimated. Logistic and linear regression models were used, taking into account potential confounders: age; gender; marital status; education; and body mass index (BMI).

Results: Energy indicators, and more particularly indicators related to noise events, were significantly associated with objective parameters of sleep quality. Increased levels of aircraft noise and increased numbers of aircraft noise events increased the time required for sleep onset (SOL) and the total wake time after sleep onset (WASO), and decreased sleep efficiency (SE). An association was also observed between aircraft noise exposure and an increase in total sleep time (TST) and time in bed (TB). 
Conclusion: The findings of the present study contribute to the overall evidence suggesting that nocturnal aircraft noise exposure may decrease objective quality of sleep. Aircraft noise exposure affects objective parameters of sleep quality, not only in terms of noise levels but also in terms of number of events. Mechanisms for adapting to sleep deprivation could be observed.

Key words: Epidemiology; aircraft noise exposure; sleep quality; actigraphy 


\section{Highlights}

Aircraft noise exposure at night may decrease objective quality of sleep.

Energy and noise event indicators affect objective parameters of sleep quality.

Mechanisms for adapting to sleep deprivation could be observed. 


\section{INTRODUCTION}

Sleep is fundamental to health and well-being, to physical and psychological balance. It can be disturbed or interrupted by a variety of stimuli, in particular noise. According to the European Environment Agency (EEA), about 125 million European urban dwellers are exposed to environmental noise at levels considered disturbing and which can affect their health [1]. Transportation is the source of most environmental noise.

Sleep disorder is the most serious consequence of environmental noise in Western Europe [2]. According to the World Health Organization (WHO), it is the cause of 903,000 healthy life years lost each year in Europe [3]. Laboratory and field studies have convincingly established that exposure to transportation noise, notably aircraft noise, disturbs sleep. Exposure to noise at night degrades the quality of sleep at both the subjective and objective level [4], [5]. It can prolong the time needed to fall asleep by up to almost 20 minutes [6]. It provokes intermittent and premature awakening, changes of sleep stage, movements of the body, changes to posture and responses by the autonomic nervous system. It increases total waking time to the detriment of deep sleep and/or rapid eye movement (REM) sleep, and reduces total sleep duration [4], [7]-[12]. At the subjective level, a reduction in self-estimated sleep quality and a worsening of mood and performance were observed [13]-[15], as well as an increase in selfdeclared sleep disorder and medication [2].

In the vicinity of airports, the majority of studies have assessed subjective sleep quality through questionnaires. Some studies, far less numerous, have measured the objective parameters of sleep quality at the participants' homes. It is important to focus not only on the subjective quality of sleep as reported by the subjects themselves, but also on the objective parameters of sleep. Some authors noted a connection between exposure to noise and the objective quality of sleep, but no connection with the subjective quality [16]. Furthermore, 
some studies showed habituation to noise in the subjective quality of sleep, but not in the objective parameters [17], [18]. However, most studies dealing with objective sleep parameters were carried out in laboratories on young people in good health [12]. Epidemiological studies covering the entire population exposed to aircraft noise are needed for more inclusive and accurate description of its effects on sleep.

Likewise, the majority of studies carried out in the vicinity of airports used data on noise exposure determined by units of sound energy at the exterior of dwellings, estimated by modeling. The original aspect of this study is that it uses precise data drawn simultaneously from measurements taken both outside and inside the dwellings. This enables simultaneous generation of sound energy and event indicators representative of real exposure of residents to ambient noise such as that produced by aircraft overflights.

In France, studies assessing the effects of exposure to aircraft noise on the sleep quality of residents near airports are few in number and they measured only the subjective quality of sleep with survey questionnaires. Mindful of this, the aim of this study was to better understand and better quantify the effects of aircraft noise on objective parameters of sleep quality of residents living in the vicinity of airports in France, while refining the measurement of noise exposure. 


\section{METHODS}

\section{Study population}

The present study is part of a wider epidemiological research program called DEBATS (Discussion sur les Effets du Bruit des Avions Touchant la Santé, or Discussion on the health effects of aircraft noise). The DEBATS study population is composed of residents aged 18 years or older and living in proximity to one of the following three French airports: ParisCharles de Gaulle, Lyon Saint-Exupéry, and Toulouse-Blagnac. In total, 1,244 individuals participated in the main DEBATS study, which aimed to investigate the effects of exposure to aircraft noise on health, and particularly the subjective quality of sleep [15]. The participation rate (30\%) was similar to aircraft noise studies completed in Germany, Italy, and in the UK [19]. These participants replied to a questionnaire administered by an interviewer at their place of residence. At the conclusion of the interview, the interviewer asked them if they would agree to take part in a "sleep study" survey. Subjects were excluded if they declared that they snored during sleep or shared a bedroom with a snorer. For the security of the exterior measuring equipment, participants living in a dwelling situated on the ground floor opening onto a public road were also excluded. In total, 112 volunteers signed and returned their informed consent by mail and took part in the sleep study: 91 residing near Paris-Charles de Gaulle and 21 near Toulouse-Blagnac. The participation rate was 47\% near Paris-Charles de Gaulle and 45\% near Toulouse-Blagnac. The sleep study was limited to residents in the vicinity of these two airports because a sufficient portion of their population is exposed to aircraft noise levels greater than $55 \mathrm{~dB}(\mathrm{~A})$ in terms of $\mathrm{L}_{\mathrm{den}}$. The $\mathrm{L}_{\mathrm{den}}$ is an annual noise indicator which describes the average equivalent sound pressure levels over a complete year for day (6 a.m. to 6 p.m.), evening (6 p.m. to 10 p.m.), and night (10 p.m. to 6 a.m.) where evening and night sound pressure levels receive a $5 \mathrm{~dB}$ and a $10 \mathrm{~dB}$ penalty, respectively. The 
$L_{d e n}$ is the "general purpose" indicator defined in the EU directive 2002/49 relating to the assessment and management of environmental noise.

The present study was approved by two national authorities in France, the French Advisory Committee for Data Processing in Health Research and the French National Commission for Data Protection and the Liberties.

\section{Aircraft noise exposure assessment}

Exposure to aircraft noise in participants' homes was measured around the clock for one week in order to increase the probability of measuring noise under differing meteorological conditions and activity patterns of the airport hubs. Two metrological class 1 sound level meters were installed each time: the first at the exterior wall of the bedroom, $20-25 \mathrm{~cm}$ in front of the façade, in line with the bedroom window, to detect acoustic events associated with aircraft noise, the second inside the room, on the bedside table, to measure the interior noise level. Technicians set up the equipment and collect it again at the end of the study. The two sound level meters were synchronized at the beginning of the measurements. However, after the measurements, the intercorrelation between both signals was calculated in order to check the temporal synchronization. If needed, the time lag was corrected. Bruitparif (the noise observatory for the Paris area (Île-de-France)) developed an algorithm that enables calculation of the aircraft noise level inside the room, based on these measurements. The first step of the algorithm consists in determining, from the outdoor signal measured on the outer wall of the building, the acoustic events associated with aircraft overflight, based on correspondence between the radar trajectories supplied by the French Civil Aviation Authority (Direction Générale de l'Aviation Civile: DGAC) and the observed acoustic events. The second step, based on the measurement taken inside the room, determined the periods affected by aircraft noise, by correlation with the times of acoustic events identified as aircraft noise in the 
outdoor measurement. The third step consisted in estimation of an exterior/interior transfer function, identifying acoustic signals in the room caused exclusively by the exterior noise. The final stage consisted in statistical analysis of time-matched curves for exterior and interior sound levels at the dwelling, filtering out acoustic events originating indoors (e.g., snoring, clocks, or domestic animals) which occurred during overflight. This filtering is based on comparing the estimate of the sound signal inside the bedroom caused exclusively by exterior noise (using the transfer function) to the sound signal measured in the bedroom. A significant difference between the two signals corresponds to the presence of an indoor noise. Filtering in this way was necessary in order to produce reliable estimates of indicators linked to noise inside the bedroom generated by the overflight of aircraft.

Many acoustic indicators were derived from these measurements. They were estimated for all sources of noise, but also for aircraft noise only, during the participant's sleep period, from falling asleep to final awakening. A distinction was made between energy indicators (related to the sound energetic average for a given period of time) and event indicators (characteristics and number of events exceeding a given sound level). Energy indicators notably included equivalent continuous acoustic pressure level (LAeq for all sources of noise and LAeq,aero for aircraft noise only) at the interior (LAeq,int for all sources of noise and LAeq,aero,int for aircraft noise only) and exterior (LAeq,ext for all sources of noise and LAeq,aero,ext for aircraft noise only) of the bedroom. This is the average energy level for a given period, and corresponds to a "noise dose" received during a set period. The contribution of aircraft noise to the total level of interior (\%Contrib,aero,int = LAeq,aero,int $/$ LAeq,int $\mathbf{x} 100$ ) and exterior (\%Contrib,aero,ext $=$ LAeq,aero,ext $/$ LAeq,ext x 100) bedroom noise were each assessed. The following event indicators were determined: the total number of aircraft noise events in the interior (NA,int) and exterior (NA,ext) of the bedroom; the number of sound events exceeding $30 \mathrm{~dB}(\mathrm{~A})$ attributable to aircraft overflight, inside the bedroom (NA30,int), 
and exceeding $62 \mathrm{~dB}(\mathrm{~A})$ on the outside (NA62,ext). Another indicator, called the Harmonica index (Indice Harmonica), was calculated for the total ambient noise at the exterior of the dwelling during the sleep period. This is a noise indicator derived by Bruitparif under the European environmental program, LIFE; it gives summary information on the level of sound pollution on a scale of 0 to 10 (the higher the grade, the greater the acoustic environment impairment) and a graphic representation based on the two components of the Harmonica index: the first component is linked to background noise and the second to sound events that emerge from this background noise [20]. This graphic representation neatly illustrates whether a noise is continuous or strongly event-related.

\section{Sleep assessment}

Each participant wore a wrist actigraph during the period of acoustic instrumentation and completed a sleep diary the day after each night. The actigraph records the activity-rest cycle and this enables assessment of the sleep-wake rhythm. It comprises a sensor that detects accelerations linked to movement. A piezoelectric quartz sensor measures the pulse accelerations on the wrist that generate variable tension with each movement of the subject. These accelerations, above a given threshold, are counted in intervals of one minute and stored with their time of occurrence. Recorder calibration and review and analysis of data are performed through a computer interface. Classification by periods of activity or sleep depends on the sensitivity level of the algorithm. In the present study, a "high" sensitivity of the actigraph with a period of one minute was used: a total of 20 movements was sufficient to designate a period as “awake” [21], [22].

Actigraphy, coupled with analysis of the sleep diary, allowed objective determination of sleep schedule parameters: beginning, end, length, and assessment of motor activity over the course of sleep. Participants did not need to adhere to specific sleep times during the study period. 
They should behave as much as possible as usual in order to collect sleep parameters that were representative of everyday life. In this study, the following objective parameters of sleep were determined through actimetric measurement:

- $\quad$ Sleep Onset latency (SOL): time between putting out the lights and falling asleep;

- $\quad$ Wake After Sleep Onset (WASO): the total duration of awakenings during sleep;

- $\quad$ Time in Bed (TB): time spent in bed between putting out the lights and finally getting up;

- $\quad$ Total Sleep Period (TSP): time between falling asleep and finally waking up;

- $\quad$ Total Sleep Time (TST): time between falling asleep and finally waking up, reduced by the total duration of awakenings during sleep;

- $\quad$ Sleep Efficiency (SE): total sleep time (TST) / total sleep period (TSP).

All these parameters were dichotomized in order to be linked to aircraft noise exposure. According to the third edition of International Classification of Sleep Disorders (ICSD-3) [23], a sleep onset latency of more than 30 minutes for an adult is considered sleep onset insomnia. The sleep onset latency variable was therefore dichotomized as SOL $\geq 30 \mathrm{~min}$ versus SOL $<30 \mathrm{~min}$. Wake After Sleep Onset was dichotomized as WASO $\geq 30 \mathrm{~min}$ versus WASO < 30 min: according to the ICSD-3, being awake for a total of more than 30 minutes is characteristic of sleep maintenance insomnia. Time in Bed was dichotomized as TB $>9 \mathrm{hr}$ versus $\mathrm{TB} \leq 9 \mathrm{hr}$ in order to study the time that subjects spend in bed. Total Sleep Period (TSP) and Total Sleep Time (TST) were dichotomized as "short sleep" $(<6 \mathrm{hr})$ versus "normal or long sleep" ( $\geq 6 \mathrm{hr}$ ): adult sleep of less than 6 hours per night on workdays is generally considered as short sleep, with potential comorbidities [24], [25]. Sleep Efficiency (SE) was dichotomized as $<90 \%$ versus $\geq 90 \%$ : an SE score $<90 \%$ is characteristic of insomnia. 


\section{Statistical analyses}

In order to take into account the clustered nature of the data, correlation coefficients between the noise indicators and the objective parameters of sleep quality were calculated using the repeated measures correlation (rmcorr) $\mathrm{R}$ package $\underline{\text { https://cran.r- }}$ project.org/web/packages/rmcorr/ [26]. Risk factors known in the literature as liable to influence sleep were collected either by questionnaire or by objective measurement by the investigators, and were included in the final multivariate analyses: gender; age; marital status; educational qualifications; and body mass index (BMI). Initially, time in bed was also included in the multivariate regression model. However, it did not contribute significantly to the model and did not have any impact on the effect estimate of noise, so it was not included in the final model.

Logistic regression models that take into account data clustering were then executed, treating the objective parameters of sleep as dependent variables, and the acoustic indicators and the previously cited potential confounding factors as covariables, in order to assess the effects of aircraft noise exposure on objective parameters of sleep quality as measured by actigraphy. The models were separately adjusted for each acoustic indicator. Linear regression models were also used to estimate the association between aircraft noise exposure and objective sleep parameters. These models were adjusted on the same confounders as those included in the logistic regression models.

Sensitivity analyses were carried out, separating weekdays from the two days of the weekend. Sleep medication use was also included in the models as a confounding factor.

The analyses were carried out using SAS Version 9.4 software 2014 (Cary, North Carolina, USA). 


\section{RESULTS}

Table 1 describes the participants in the sleep study and compares them to the 1,244 participants in the main DEBATS study. The two populations were relatively similar, although participants in the sleep study were a little younger than those in the principal DEBATS study (30\% and $42 \% \geq 55$ years, respectively). Table 2 describes the acoustic indicators and the objective parameters of sleep quality. The equivalent continuous noise level, all sources of noise combined, was on average $51 \mathrm{~dB}(\mathrm{~A})$ at the exterior (LAeq,ext) of the bedroom and $33 \mathrm{~dB}(\mathrm{~A})$ at the interior (LAeq,int). The equivalent continuous aircraft noise levels at the exterior (LAeq,aero,ext) and interior (LAeq,aero,int) of the participants' bedrooms were respectively $44 \mathrm{~dB}(\mathrm{~A})$ and $17 \mathrm{~dB}(\mathrm{~A})$. On average, 37 aircraft noise events were detected at the exterior (NA,ext) and 29 at the interior of the bedroom (NA,int) during the sleep period. Total sleep time (TST) per night was on average 6 hours 56 minutes, with an average sleep onset latency (SOL) of 35 minutes. The average sleep efficiency (SE) was 94\%. No differences were observed between weekdays and weekends for acoustic indicators. For the objective sleep parameters, the participants slept more on weekends than during the week, with total sleep time (TST) of respectively 7 hours 16 minutes and 6 hours 48 minutes. They spent more time in bed (TB) on weekends (8 hours 54 minutes) than during the week (8 hours 24 minutes), with slightly higher sleep efficiency (SE) on weekends ( $94.2 \%$ vs $93.8 \%$ for the working week).

Table 3 shows that $18 \%$ of individuals slept less than 6 hours per night (TST). Almost $45 \%$ of participants showed sleep onset insomnia ( $\mathrm{SOL} \geq 30 \mathrm{~min}$ ) or sleep maintenance insomnia (WASO $\geq 30 \mathrm{~min}$ ). About 13\% of participants had poor sleep efficiency (SE score $<90 \%$ ).

Table 4 presents the correlations between the acoustic indicators and the objective sleep parameters. Significant positive correlations were obtained between the acoustic indicators, 
whether energy indicators or event indicators, and TB, TSP, TST and WASO. The more the level or number of aircraft noise events increased, the more time was spent in bed (TB), and the duration of TSP, TST and WASO increased. Weakly significant negative correlations were observed between the acoustic indicators and sleep efficiency (SE): increase in the level of aircraft noise exposure degraded sleep efficiency. Significant correlations were shown between the Harmonica index and all the objective sleep parameters except SOL.

The odds ratios (ORs) and their confidence intervals (95\% CI) derived from logistic regression models between acoustic indicators and objective sleep parameters are shown in Table 5. Unadjusted and adjusted findings were very similar. A significant positive relationship was found between the energy and event indicators of exposure to aircraft noise (except for \%Contrib,aero,int) and TB and TSP: an increase in aircraft noise or the number of aircraft noise events in both the interior and exterior of the bedroom increased the probability of spending more than 9 hours in bed (TB) and of sleeping more than 6 hours (TSP). All of the energy and event indicators of exposure to aircraft noise were significantly positively related to TST. A significant positive relationship was found between all of the energy indicators (except LAeq,aero,ext) and sleep onset latency (SOL): an increase of $10 \mathrm{~dB}(\mathrm{~A})$ in the equivalent level of noise inside the room (LAeq,aero,int) was associated with an increase in SOL (OR=1.26, 95\% CI: 1.00-1.60). With regard to wake after sleep onset (WASO), significant positive relationships were found for all the event indicators: an increase of 10 aircraft noise events exceeding $30 \mathrm{~dB}(\mathrm{~A})$ inside the bedroom was associated with an increase in the total WASO (OR=1.09, 95\% CI : 1.03-1.16). ORs between acoustic indicators and sleep efficiency (SE) indicated deterioration in SE with increasing level or number of aircraft noise events; however, these associations were not significant when confounders were included in the models. ORs between the Harmonica index and the objective sleep parameters were in the same direction as for the other acoustic indicators. Deterioration in the soundscape 
was significantly associated with an increase in TB, TSP, TST and WASO, and a reduction in sleep efficiency.

The results were very similar when linear regression models were used instead of logistic regression models (supplementary table).

There was no difference in these associations between weekdays and weekends (results not shown).

The results remained similar if the models included sleep medication use as a potential confounding factor (results not shown). 


\section{DISCUSSION}

This field study is the first in France to investigate a relationship between exposure to aircraft noise and objective sleep quality assessed by means of actimetric measurement. It included 112 participants for a total of 911 instrumentation days (an average of 8 instrumentation days per subject). The average total sleep period (TSP) of participants (7 hours 16 minutes on weekdays and 7 hours 43 minutes at the weekend) was similar to that of the general French population. According to a survey by the Institut National du Sommeil et de la Vigilance (National Institute of Sleep and Alertness) in late 2016 [27], the French sleep on average 7 hours and 7 minutes during the week and 8 hours and 4 minutes at the weekend. Therefore, in line with the literature, the duration of sleep at weekends is longer than on weekdays [28]. However, the difference in sleep duration between weekends and weekdays was smaller for participants in our study than for the French population as a whole (27 minutes versus 57 minutes). Given that nocturnal exposure to aircraft noise is comparable on weekends and weekdays, the potential for longer sleep on weekends was presumably limited. On the other hand, the average sleep onset latency of the participants (35 minutes) was higher than that of the general population (24 minutes) [27], even if it is rough to compare sleep onset latency estimated with actigraphy with survey estimates. The prevalence of short sleepers (TST < 6 hours) in this study (18\%) was similar to the estimate in the 2010 INPES (National Institute for Prevention and Health Education) "Health barometer” (Baromètre santé) (also 18\%) [29]. The sound level for all sources of noise combined measured in the bedrooms of participants during sleep periods (LAeq,int) was on average $33 \mathrm{~dB}(\mathrm{~A})$, relatively similar to the level recommended by the WHO for inside bedrooms (30 dB(A)) [2]. About $67 \%$ of our study's population were exposed to noise levels inside the room averaging more than $30 \mathrm{~dB}(\mathrm{~A})$.

Several studies have been conducted around large airports, particularly in Europe, in order to investigate the effects of aircraft noise exposure on the sleep of residents. The majority of 
these studies concerned the subjective quality of sleep and showed that exposure to aircraft noise causes poor self-reported sleep quality, an increased feeling of fatigue on waking up in the morning and an increase in consumption of non-prescription drugs [30]-[33]. This was also the case for the main DEBATS study, which showed an association between exposure to aircraft noise and short reported sleep duration (less than 6 hours) (OR=1.63, 95\% CI: 1.152.32) for an increase of $10 \mathrm{~dB}(\mathrm{~A})$ in the level of aircraft noise, and a feeling of fatigue on waking up (OR=1.23, 95\% CI: 1.00-1.54) for an increase of $10 \mathrm{~dB}(\mathrm{~A})$ in the level of aircraft noise [15]. The majority of studies on the effects of exposure to aircraft noise on objective sleep quality parameters were carried out in laboratories, with just a few based on fieldwork. Around airport, field studies showed that exposure to aircraft noise increased sleep onset latency [32], the probability of waking [34] and movements [30], [32] and changed vegetative functions [35], [36] in those living near airports. In the laboratory, in addition to these effects, a reduction in slow-wave sleep and changes in the structure of sleep were observed [8], [37].

As with the majority of studies in the literature, the present study showed that exposure to aircraft noise caused an increase in sleep onset latency (SOL) and wake time after sleep onset (WASO) [32], [34]. Basner et al. [34] showed that exposure to aircraft noise in the vicinity of Cologne-Bonn Airport was related to an increase in the probability of awakening. An increase in time of sleep onset was observed after exposure to aircraft noise in residents living close to Amsterdam Schiphol [32].

Contrary to the majority of studies, which found that exposure to transportation noise causes a reduction in total sleep time [38], [39], the present study found increases in total sleep time (TST) and time in bed (TB). This could be a matter of behavioral adaption to sleep deprivation: as wake time after sleep onset (WASO) increases following exposure to aircraft noise, sleep efficiency (SE) is unsatisfactory. Subjects would therefore stay longer in bed in order to sleep more and recuperate. However, uncontrolled or residual confounding could also 
explain this finding. Nevertheless, an earlier laboratory study also found an increase in total sleep time after exposure to aircraft noise [37]. The authors interpreted this as adaptation to partial sleep deprivation during previous nights when the subjects were exposed to noise [37]. Ohrstrom and Skanberg also observed a significant reduction in total sleep time and time in bed, as measured by actigraphy, after a reduction in road traffic at night [40]. The authors explained this reduction as the result of long wake times and by the fact that the individuals were probably much less tired after the reduction in nocturnal traffic [40].

Some studies showed that sleep habits differed between weekdays and weekends [41], [42]. In spite of these differences, the relationships we observed between exposure to aircraft noise and objective sleep parameters were the same on weekdays and on the weekend.

The participants in this study were recruited from subjects who had taken part in the main DEBATS study. Participants in the main study were randomly selected, but those who participated in our sleep study were volunteers. It could therefore be that they were the most concerned and bothered by noise nuisances. The prevalence of subjects reporting poor sleep was $43 \%$ in the sleep study, while it was $32 \%$ in the main DEBATS study. In the present study, 32\% of subjects also reported feeling tired on waking up in the morning, compared to $30 \%$ in the main study. Concerning annoyance, $24 \%$ of participants in the present study reported being extremely or bothered by aircraft noise while the corresponding figure in the main DEBATS study was $18 \%$. Thus, a slight selection bias probably cannot be ruled out in interpreting the results of the sleep study.

The first strength of the present study was the estimation of the objective sleep quality parameters by means of an actigraph which participants wore on their wrists. Actimetric recording has rarely been used in epidemiological studies. Polysomnography is the laboratory reference method. Its high cost and the practical difficulties linked to its implementation in the 
dwellings of participants have meant that few field studies have used this method. Actigraphy is easy to perform in a larger sample while preserving the sleep habits of participants in their homes. It cannot only estimate objective parameters of sleep quality, such as TST and WASO [43], but also diagnose certain sleep problems [44]. Martoni et al. showed that actigraphy and ambulatory polysomnography can produce similar results concerning chronic insomnia [45]. O’Driscoll et al. demonstrated that actigraphy provides a correct indication of the level of sleep fragmentation in children [46]. However, there are uncertainties regarding the assessment of objective sleep parameters through actigraphy. A review of the literature by Martin and Hakim showed that actigraphy was of limited use compared to polysomnography in estimating sleep onset latency (SOL), in particular for subjects suffering from a sleep disorder [43]. Furthermore, actigraphy defines awakening as a certain number of movements per unit of time. In the present study the threshold was 20. This definition can lead to a classification bias: an individual who is totally immobile but is in fact awake is considered as being in a sleep phase, and an individual making a large number of movements is treated as being awake, while in reality they may be asleep. Nonetheless, one can reasonably hope that this bias is independent of exposure to aircraft noise, and would have led to under-estimation of the associations observed in this study. It has also been shown that actigraphy had less validity when the actigraph was worn only in bed [44]. This was not the case in this study, since participants wore the actigraph throughout the instrumentation period, by day as well as by night, which strengthens the validity of the values obtained for the sleep parameters. Moreover, actimetric assessment was completed using information reported by the participants in a sleep diary they filled out each morning. Data from this sleep diary enabled adjustment and correction of any irregularities in the actimetric measurements.

The second strength of this study concerns the acoustic measurements from which acoustic indicators were estimated. These measurements were performed at the homes of the 
participants, both inside and outside their bedrooms. Estimation of indicators from the inside of the dwelling made it possible to take into account any sound insulation of the building, and the practice of opening and closing windows, while French and European Union regulations, and also other epidemiological studies that have been carried out to date, were based on noise exposure at building exteriors, despite the fact that aircraft noise measured indoors was shown to be more closely related to sleeping problems than levels measured outdoors [47]; this review of the literature of field studies of sleep problems induced by exposure to aircraft noise indicated that, in almost all cases where acoustic measurements were made at the outside of the dwelling, outdoor sound levels were not predictive of sleep disorder. This does not apply to the present study: acoustic measurements both inside the bedroom and at the exterior were associated with objective sleep parameter values.

The acoustic measurements also allowed us to estimate not just energy indicators but also event indicators to characterize aircraft noise exposure, while almost all epidemiological studies on the subject used only energy indicators. Although energy indicators are recommended by the European Directive of 2002 [48] relating to the management of environmental noise, event indicators are currently recommended for studies on the effects of noise on sleep, because they can better characterize aircraft noise [49]. The present study found that, contrary to the energy indicators, the event indicators were significantly related to almost all objective parameters of sleep quality that were considered. These results confirm those obtained by Ohrstrom and Rylander, that the number of road traffic noise events had a considerably more significant effect on the quality of sleep, assessed objectively and subjectively, than did the continuous noise level [50]. Griefahn et al. also showed, in a laboratory study, that the equivalent level of noise (LAeq) of transport (road, rail and aviation) was a good predictor of subjectively assessed sleep quality, but not of physiological sleep problems such as awakenings [51]. The WHO also pointed out that event indicators 
seemed to be more predictive of sudden short-term effects, such as movement onset, awakening, cardiovascular response and change in sleep stage [2]. 


\section{CONCLUSION}

This study is the first in France and one of only few in Europe to investigate an association between exposure to aircraft noise and objective sleep quality assessed by actimetric measurements at the homes of residents near airports. Its results confirm that exposure to aircraft noise affects the objective parameters of sleep quality, with an increase in time of sleep onset and duration of wake after sleep onset, and a reduction in sleep efficiency. It also increases total sleep time and time in bed: this could be a matter of behavioral adaption to sleep deprivation. The results also support the hypothesis that acoustic event indicators can better characterize the effects of aircraft noise on sleep than the more widely used energy indicators. 


\section{Acknowledgements}

The Airport Pollution Control Authority (Acnusa) requested the French Institute of Science and Technology for Transport, Development and Networks (Ifsttar) for carrying out this study. The authors would like to thank them for their confidence in them.

They are grateful to all the participants in the study.

They also thank Paris Airports and the French Civil Aviation Authority for providing noise exposure maps. They are also grateful to Inès Khati for her participation in the implementation of the study, and to Iain McGill for the translation of the manuscript from French into English.

\section{Funding}

The present study was supported by funds from the French Ministry of Health, the French Ministry of Environment, and the French Civil Aviation Authority. We would like to thank them for their kind assistance.

\section{Competing interests}

None. 


\section{REFERENCES}

[1] European Environment Agency. Noise in Europe 2014. Luxembourg: Publications Office; 2014.

[2] WHO. Night noise guidelines for Europe. Copenhagen, Denmark: World Health Organization Europe; 2009.

[3] WHO. Burden of disease from environmental noise: quantification of healthy life years lost in Europe. Copenhagen: World Health Organization, Regional Office for Europe; 2011.

[4] Griefahn B, Scheuch K, Jansen G, et al. Protection goals for residents in the vicinity of civil airports. Noise Health Jul. 2004;6(24):51-62.

[5] Halperin D. Environmental noise and sleep disturbances: a threat to health? Sleep Sci Dec. 2014;7(4):209-12.

[6] Öhrström E. Research on noise since 1988: present state, vol. 1. Nice: INRETS; 1993.

[7] Griefahn B, Spreng M. Disturbed sleep patterns and limitation of noise. Noise Health Jan. 2004;6(22):27-33.

[8] Basner M, Glatz C, Griefahn B, et al. Aircraft noise: effects on macro- and microstructure of sleep. Sleep Med May 2008;9(4):382-7.

[9] Popp RF, Maier S, Rothe S, et al. Impact of overnight traffic noise on sleep quality, sleepiness, and vigilant attention in long-haul truck drivers: results of a pilot study, vol. $17 ; 2015$.

[10] Hume KI, Brink M, Basner M. Effects of environmental noise on sleep. Noise Health Nov. 2012;14(61):297-302.

[11] Morrell S, Taylor R, Lyle D. A review of health effects of aircraft noise. Aust N Z J Public Health Apr. 1997;21(2):221-36. 
[12] Perron S, Tetreault LF, King N, et al. Review of the effect of aircraft noise on sleep disturbance in adults. Noise Health Mar. 2012;14(57):58-67.

[13] Waye KP, Clow A, Edwards S, et al. Effects of nighttime low frequency noise on the cortisol response to awakening and subjective sleep quality. Life Sci Jan. 2003;72(8):863-75.

[14] Stosic L, Belojevic G, Milutinovic S. Effects of traffic noise on sleep in an urban population. Arh Hig Rada Toksikol Sep. 2009;60(3):335-42.

[15] Nassur A-M, Lefèvre M, Laumon B, et al. Aircraft noise exposure and subjective sleep quality: the results of the DEBATS study in France. Behav Sleep Med Nov. 2017;0(0):112.

[16] Frei P, Mohler E, Roosli M. Effect of nocturnal road traffic noise exposure and annoyance on objective and subjective sleep quality. Int J Hyg Environ Health Mar. 2014;217(2-3):188-95.

[17] Kuroiwa M, Xin P, Suzuki S, et al. Habituation of sleep to road traffic noise observed not by polygraphy but by perception. J Sound Vib 2002;250(1):101-6.

[18] Eberhardt JL, Akselsson KR. The disturbance by road traffic noise of the sleep of young male adults as recorded in the home. J Sound Vib 1987;114(3):417-34.

[19] Jarup L, Babisch W, Houthuijs D, et al. Hypertension and exposure to noise near airports: the HYENA study. Environ Health Perspect 2008;116(3):329-33.

[20] Mietlicki F, Mietlicki C, Ribeiro C, et al. New tools to inform the public about environmental noise in cities and to assist decision-making. In: Euro Noise, Maastricht; 2015.

[21] Someren EJWV. Improving actigraphic sleep estimates in insomnia and dementia: how many nights? J Sleep Res Sep. 2007;16(3):269-75. 
[22] Elbaz M, Yauy K, Metlaine A, et al. Validation of a new actigraph motion watch versus polysomnography on 70 healthy and suspected sleep-disordered subjects. J Sleep Res 2012;21(1):218.

[23] International classification of sleep disorders e 3rd ed. (ICSD-3). 3rd ed. American Academy of Sleep Medicine; 2014.

[24] Cappuccio FP, D'Elia L, Strazzullo P, et al. Sleep duration and all-cause mortality: a systematic review and meta-analysis of prospective studies. Sleep May 2010;33(5):58592.

[25] Kurina LM, McClintock MK, Chen J-H, et al. Sleep duration and all-cause-mortality: a critical review of measurement and associations. Ann Epidemiol Jun. 2013;23(6):36170.

[26] Bakdash JZ, Marusich LR. Repeated measures correlation. Front Psychol Apr. 2017;8.

[27] 'Enquête INSV/MGEN “Dormir seul ou pas : quel impact sur le sommeil ?”’. Institut National du Sommeil et de la Vigilance; 2017 [Online]. Available: http://www.institutsommeil-vigilance.org/la-journee-du-sommeil-2 [Accessed 5 April 2018].

[28] Thorleifsdottir B, Björnsson J, Benediktsdottir B, et al. Sleep and sleep habits from childhood to young adulthood over a 10-year period. J Psychosom Res Jul. 2002;53:52937.

[29] Leger D, Beck F, Richard JB, et al. The risks of sleeping “too much.” Survey of a national representative sample of 24671 adults (INPES health barometer). PLoS One 2014;9(9):e106950.

[30] Janssen SA, Centen MR, Vos H, et al. The effect of the number of aircraft noise events on sleep quality. Appl Acoust 2014;84:9-16. 
[31] Kim SJ, Chai SK, Lee KW, et al. Exposure-response relationship between aircraft noise and sleep quality: a community-based cross-sectional study. Osong Public Health Res Perspect Apr. 2014;5(2):108-14.

[32] Passchier-Vermeer W, Vos H, Steenbekkers J, et al. TNO report 2002. Sleep disturbance and aircraft noise exposure: exposure-effect relationships, vol.027. The Netherlands: Division Public Health; Jun. 2002.

[33] Franssen EA, van Wiechen CM, Nagelkerke NJ, et al. Aircraft noise around a large international airport and its impact on general health and medication use. Occup Environ Med May 2004;61(5):405-13.

[34] Basner M, Samel A, Isermann U. Aircraft noise effects on sleep: application of the results of a large polysomnographic field study. J Acoust Soc Am May 2006;119(5 Pt 1):2772-84.

[35] Aydin Y, Kaltenbach M. Noise perception, heart rate and blood pressure in relation to aircraft noise in the vicinity of the Frankfurt airport. Clin Res Cardiol Jun. 2007;96(6):347-58.

[36] Schmidt FP, Basner M, Kr€oger G, et al. Effect of nighttime aircraft noise exposure on endothelial function and stress hormone release in healthy adults. Eur Heart $\mathrm{J}$ Dec. 2013;34(45). 3508-14a.

[37] Basner M, Samel A. Effects of nocturnal aircraft noise on sleep structure. Somnologie May 2005;9(2):84-95.

[38] Muzet A. Environmental noise, sleep and health. Sleep Med Rev Apr. 2007;11(2):13542.

[39] Pirrera S, De Valck E, Cluydts R. Nocturnal road traffic noise: a review on its assessment and consequences on sleep and health. Environ Int Jul.2010;36(5):492-8. 
[40] Öhrström E, Skånberg A. Longitudinal surveys on effects of road traffic noise: substudy on sleep assessed by wrist actigraphs and sleep logs. J Sound Vib 2004;272(3-5):1097109.

[41] Taillard J, Philip P, Bioulac B. Morningness/eveningness and the need for sleep. J Sleep Res Dec. 1999;8(4):291-5.

[42] Hale L. Who has time to sleep? J Public Health Jun. 2005;27(2):205-11.

[43] Martin JL, Hakim AD. Wrist Actigraphy. Chest Jun. 2011;139(6):1514-27.

[44] Sadeh A, Hauri PJ, Kripke DF, et al. The role of actigraphy in the evaluation of sleep disorders. Sleep Jun. 1995;18(4):288-302.

[45] Martoni M, Bayon V, Elbaz M, et al. Using actigraphy versus polysomnography in the clinical assessment of chronic insomnia (retrospective analysis of 27 patients). Press Med 2012;41(3):e95-100.

[46] O'Driscoll DM, Foster AM, Davey MJ, et al. Can actigraphy measure sleep fragmentation in children? Arch Dis Child Dec. 2010;95(12):1031-3.

[47] Michaud DS, Fidell S, Pearsons K, et al. Review of field studies of aircraft noise induced sleep disturbance. J Acoust Soc Am Jan. 2007;121(1):32-41.

[48] European Commission. EU directive on the assessment and management of environmental noise (END). The European Parliament and the Council of the European Union; 2002 [Online]. Available: http://eur-lex.europa.eu/legalcontent/EN/TXT/PDF/?uri¹/4CELEX:32002L0049\&from¹/4en [Accessed 6 April 2017].

[49] Lekaviciute Gadal J, Kephalopoulos S, Stansfeld S, et al. Final report of the ENNAH (European network on noise and health) project. Publications Office of the European Union, EUR - Scientific and Technical Research Reports; 2013.

[50] Öhrström E, Rylander R. Sleep disturbance effects of traffic noise e a laboratory study on after effects. J Sound Vib 1982;84(1):87-103. 
[51] Griefahn B, Marks A, Robens S. Noise emitted from road, rail and air traffic and their effects on sleep. J Sound Vib 2006;295(1-2):129-40. 
Table 1. Description of the 112 participants in the sleep study and of the 1,244 participants in the main DEBATS study

\begin{tabular}{|c|c|c|c|c|}
\hline & \multirow{2}{*}{\multicolumn{2}{|c|}{$\begin{array}{c}\text { Sleep study } \\
\text { N=112 }\end{array}$}} & \multirow{2}{*}{\multicolumn{2}{|c|}{$\begin{array}{c}\text { Main study } \\
\text { N=1,244 }\end{array}$}} \\
\hline & & & & \\
\hline & $\mathrm{n}$ & $(\%)$ & $\mathrm{n}$ & $\%$ \\
\hline \multicolumn{5}{|l|}{ Gender } \\
\hline Female & 65 & (58) & 695 & (56) \\
\hline Male & 47 & (42) & 549 & (44) \\
\hline \multicolumn{5}{|l|}{ Age (years) } \\
\hline $18-34$ & 32 & (29) & 226 & (18) \\
\hline $35-44$ & 19 & (17) & 236 & (19) \\
\hline $45-54$ & 27 & (24) & 266 & (21) \\
\hline $55-64$ & 17 & (15) & 260 & (21) \\
\hline $65-74$ & 9 & (8) & 185 & (15) \\
\hline $75+$ & 8 & (7) & 71 & (6) \\
\hline \multicolumn{5}{|l|}{ Marital status } \\
\hline Single & 39 & (35) & 253 & (20) \\
\hline Married & 53 & (47) & 782 & (63) \\
\hline Widowed & 4 & (4) & 76 & (6) \\
\hline Divorced & 16 & (14) & 133 & (11) \\
\hline \multicolumn{5}{|l|}{ Education } \\
\hline$<$ French high school certificate & 39 & (35) & 452 & (36) \\
\hline French high school certificate & 37 & (33) & 397 & (32) \\
\hline$>$ French high school certificate & 36 & $(32)$ & 395 & $(32)$ \\
\hline
\end{tabular}




\begin{tabular}{|c|c|c|c|c|}
\hline & \multirow{3}{*}{\multicolumn{2}{|c|}{$\begin{array}{l}\text { Sleep study } \\
\qquad \mathrm{N}=112\end{array}$}} & & \\
\hline & & & \multirow{2}{*}{\multicolumn{2}{|c|}{$\begin{array}{c}\text { Main study } \\
\text { N=1,244 }\end{array}$}} \\
\hline & & & & \\
\hline & $n$ & $(\%)$ & $\mathrm{n}$ & $\%$ \\
\hline \multicolumn{5}{|l|}{ BMI } \\
\hline Underweight or normal weight & 58 & $(52)$ & 562 & $(46)$ \\
\hline Overweight & 41 & (37) & 4 & (34) \\
\hline Obese & 13 & (12) & 249 & (20) \\
\hline
\end{tabular}


Table 1. Description of noise indicators and objective sleep parameters

\begin{tabular}{|c|c|c|c|c|c|c|c|c|c|}
\hline & \multicolumn{5}{|c|}{ All days } & \multicolumn{2}{|c|}{ Weekdays } & \multicolumn{2}{|c|}{ Weekend } \\
\hline & Number of nights & Mean & SD & P5 & P95 & Mean & SD & Mean & SD \\
\hline Noise indicators & & & & & & & & & \\
\hline LAeq,ext (dB(A)) & 839 & 51 & 5 & 42 & 60 & 51 & 6 & 51 & 5 \\
\hline LAeq,int (dB(A)) & 840 & 33 & 7 & 24 & 47 & 33 & 7 & 33 & 7 \\
\hline LAeq,aero,ext (dB(A)) & 825 & 44 & 14 & 0 & 58 & 44 & 13 & 43 & 15 \\
\hline LAeq,aero,int (dB(A)) & 826 & 17 & 10 & 0 & 31 & 17 & 10 & 16 & 9 \\
\hline \%Contrib,aero,ext (\%) & 825 & 46 & 32 & 0 & 93 & 46 & 32 & 45 & 33 \\
\hline \% Contrib,aero,int (\%) & 826 & 11 & 16 & 0 & 46 & 11 & 17 & 11 & 16 \\
\hline N,ext & 825 & 37 & 36 & 0 & 99 & 37 & 36 & 38 & 38 \\
\hline $\mathrm{N}$,int & 826 & 29 & 30 & 0 & 84 & 28 & 30 & 30 & 32 \\
\hline NA62,ext & 825 & 25 & 30 & 0 & 79 & 24 & 29 & 28 & 33 \\
\hline NA30,int & 826 & 25 & 29 & 0 & 79 & 25 & 28 & 26 & 31 \\
\hline Harmonica & 786 & 5 & 1 & 3 & 7 & 5 & 1 & 5 & 1 \\
\hline
\end{tabular}




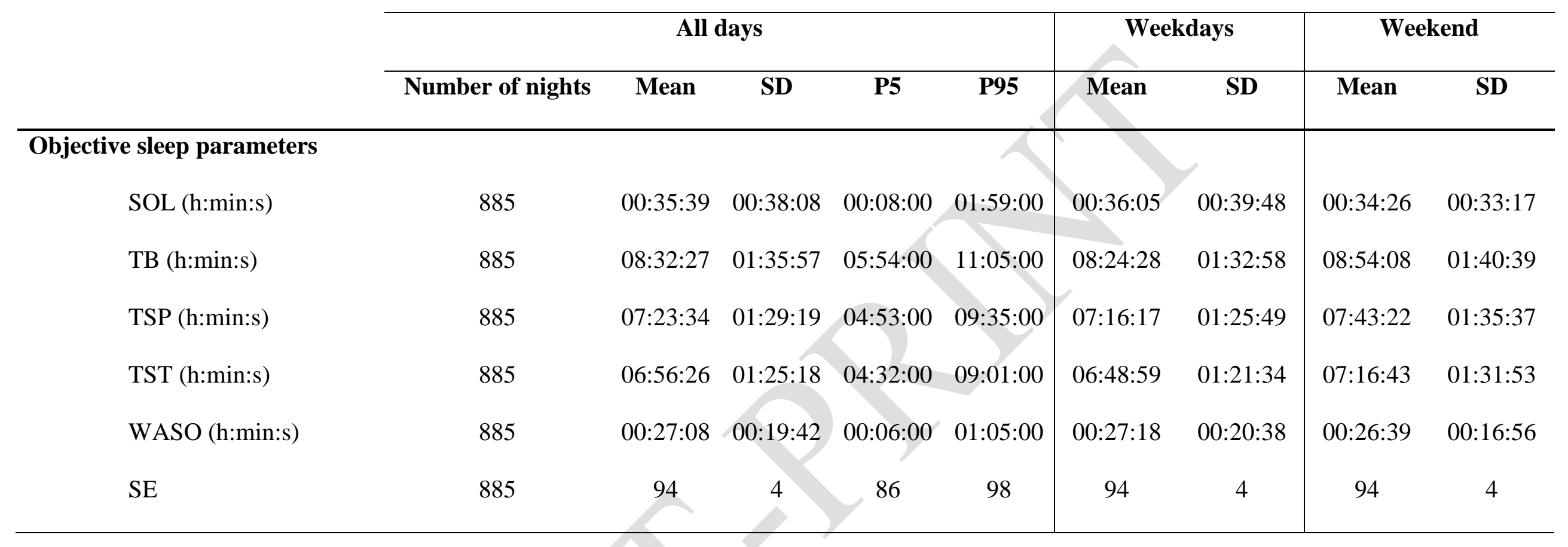


Table 2. Distribution of the participants according to objective sleep parameters

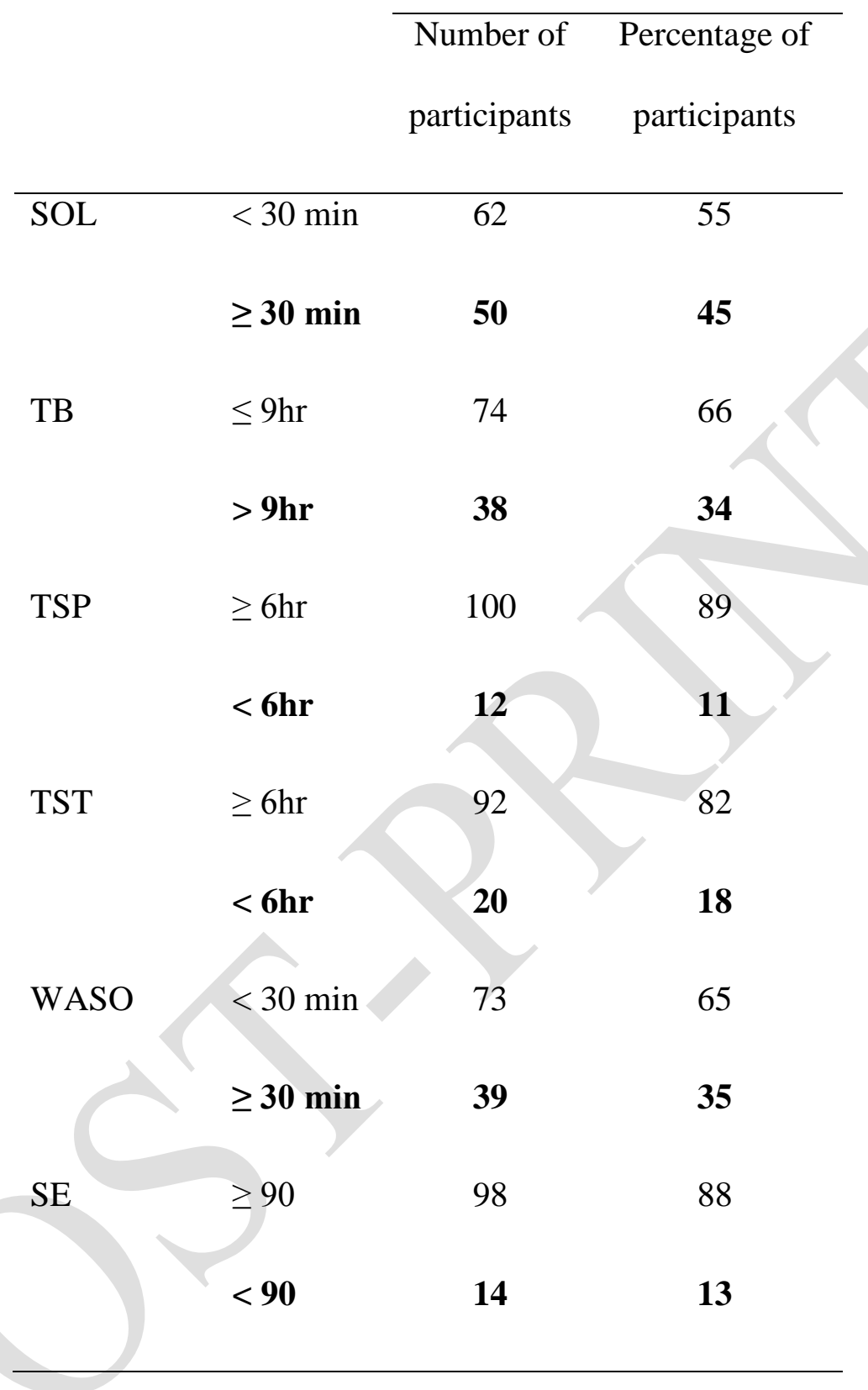


Table 3. Correlations between noise indicators and objective sleep parameters

\begin{tabular}{cccccc}
\hline SOL & TB & TSP & TST & WASO & SE \\
\hline$r^{*}(p$-value $)$ & $r^{*}($ p-value $)$ & $r^{*}(p$-value $)$ & $r^{*}(p$-value $)$ & $r^{*}(p-v a l u e)$ & $r^{*}$ (p-value $)$
\end{tabular}

\begin{tabular}{|c|c|c|c|c|c|c|}
\hline \multicolumn{7}{|l|}{ Integrated indicators } \\
\hline LAeq,aero,ext & $-0,04(0,32)$ & $0,21(<0,001)$ & $0,25(<0,001)$ & $0,24(<0,001)$ & $0,15(<0,001)$ & $-0,09(0,01)$ \\
\hline LAeq,aero,int & $0,01(0,79)$ & $0,17(<0,001)$ & $0,17(<0,001)$ & $0,16(<0,001)$ & $0,11(0,002)$ & $-0,08(0,03)$ \\
\hline \%Contrib aero,ext & $0,02(0,53)$ & $0,12(0,001)$ & $0,10(0,006)$ & $0,10(0,01)$ & $0,07(0,07)$ & $-0,05(0,21)$ \\
\hline$\%$ Contrib,aero ,int & $0,01(0,71)$ & $-0,04(0,27)$ & $-0,05(0,15)$ & $-0,04(0,33)$ & $-0,1(0,005)$ & $0,06(0,09)$ \\
\hline \multicolumn{7}{|l|}{ Noise event indicators } \\
\hline N,ext & $-0,09(0,01)$ & $0,45(<0,001)$ & $0,52(<0,001)$ & $0,52(<0,001)$ & $0,20(<0,001)$ & $-0,03(0,37)$ \\
\hline $\mathrm{N}$,int & $-0,07(0,08)$ & $0,36(<0,001)$ & $0,41(<0,001)$ & $0,41(<0,001)$ & $0,18(<0,001)$ & $-0,05(0,20)$ \\
\hline NA62,ext & - 0,09 (0,02) & $0,36(<0,001)$ & $0,41(<0,001)$ & $0,41(<0,001)$ & $0,16(<0,001)$ & $-0,03(0,48)$ \\
\hline NA30,int & $-0,06(0,12)$ & $0,33(<0,001)$ & $0,37(<0,001)$ & $0,36(<0,001)$ & $0,16(<0,001)$ & $-0,04(0,28)$ \\
\hline Harmonica & $0,004(0,91)$ & $0,19(<0,001)$ & $0,21(<0,001)$ & $0,20(<0,001)$ & $0,13(0,001)$ & $-0,08(0,05)$ \\
\hline
\end{tabular}


$* r$ :

Bold values are statistically significant $p<0.05$. 
Table 5. Odds ratios for the relationship between noise indicators and objective sleep parameters

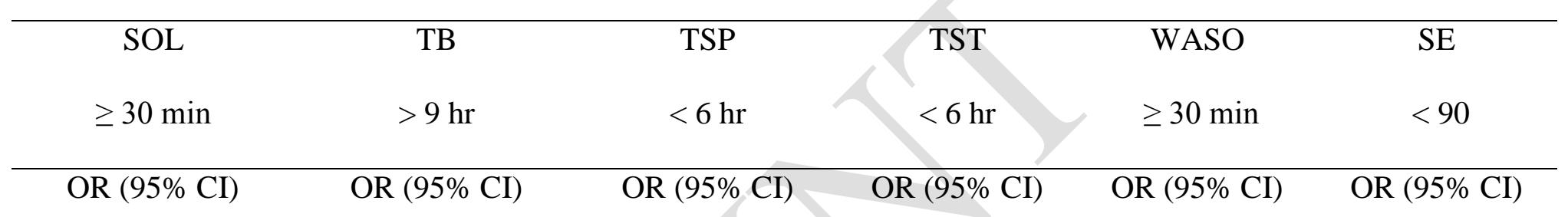

\begin{tabular}{|c|c|c|c|c|c|c|}
\hline \multicolumn{7}{|l|}{ Integrated indicators } \\
\hline \multicolumn{7}{|l|}{ Crude estimates } \\
\hline LAeq.aero.ext ${ }^{1}$ & $1.07(0.93-1.23)$ & $1.36(1.12-1.65)$ & $0.73(0.64-0.83)$ & $0.72(0.62-0.83)$ & 1.22 (1.07-1.39) & $1.23(0.89-1.69)$ \\
\hline LAeq.aero.int ${ }^{1}$ & 1.27 (1.02-1.59) & $1.53(1.24-1.88)$ & $0.60(0.47-0.75)$ & $0.61(0.49-0.75)$ & $1.10(0.91-1.33)$ & $1.40(0.97-2.02)$ \\
\hline$\%$ Contrib.aero.ext ${ }^{2}$ & $1.08(1.02-1.16)$ & $1.08(1.02-1.15)$ & $0.89(0.82-0.97)$ & $0.91(0.84-0.98)$ & $1.00(0.94-1.05)$ & $1.09(1.00-1.18)$ \\
\hline$\%$ Contrib.aero.int $^{2}$ & $1.23(1.09-1.38)$ & $1.03(0.93-1.14)$ & $0.88(0.72-1.09)$ & $0.86(0.74-1.00)$ & $0.88(0.77-1.01)$ & $1.07(0.94-1.22)$ \\
\hline \multicolumn{7}{|l|}{ Adjusted estimates* } \\
\hline LAeq.aero.ext ${ }^{1}$ & $1.07(0.92-1.24)$ & $1.42(1.14-1.77)$ & $0.70(0.62-0.80)$ & $0.66(0.57-0.76)$ & $1.20(1.05-1.37)$ & $1.17(0.88-1.55)$ \\
\hline LAeq.aero.int $^{1}$ & $1.26(1.00-1.60)$ & $1.64(1.29-2.08)$ & $0.57(0.46-0.72)$ & $0.55(0.45-0.69)$ & $1.08(0.88-1.31)$ & $1.30(0.93-1.81)$ \\
\hline$\%$ Contrib.aero.ext ${ }^{2}$ & $1.09(1.02-1.16)$ & $1.09(1.02-1.16)$ & $0.88(0.81-0.96)$ & $0.89(0.83-0.96)$ & $1.00(0.90-1.10)$ & $1.06(0.97-1.16)$ \\
\hline$\%$ Contrib.aero.int $^{2}$ & $1.22(1.08-1.38)$ & $1.04(0.94-1.15)$ & $0.87(0.68-1.10)$ & $0.82(0.69-0.97)$ & $0.86(0.76-0.99)$ & $1.02(0.88-1.18)$ \\
\hline
\end{tabular}




\begin{tabular}{cccccc}
\hline SOL & TB & TSP & TST & WASO & SE \\
$\geq 30 \mathrm{~min}$ & $>9 \mathrm{hr}$ & $<6 \mathrm{hr}$ & $<6 \mathrm{hr}$ & $\geq 30 \mathrm{~min}$ & $<90$ \\
\hline OR (95\% CI) & OR (95\% CI) & OR (95\% CI) & OR (95\% CI) & OR (95\% CI) & OR (95\% CI)
\end{tabular}

\begin{tabular}{|c|c|c|c|c|c|c|}
\hline \multicolumn{7}{|l|}{ Noise events indicators } \\
\hline \multicolumn{7}{|l|}{ Crude estimates } \\
\hline N.ext ${ }^{3}$ & $1.03(0.97-1.09)$ & $1.23(1.15-1.32)$ & $0.71(0.64-0.79)$ & $0.74(0.68-0.81)$ & $1.11(1.05-1.18)$ & 1.09 (1.01-1.17) \\
\hline N.int ${ }^{3}$ & $1.05(0.98-1.12)$ & $1.23(1.14-1.32)$ & $0.68(0.60-0.78)$ & $0.73(0.66-0.81)$ & $1.10(1.03-1.16)$ & $1.10(1.01-1.20)$ \\
\hline NA62.ext ${ }^{3}$ & $1.04(0.98-1.11)$ & $1.28(1.18-1.39)$ & $0.66(0.57-0.76)$ & $0.71(0.63-0.81)$ & $1.10(1.02-1.19)$ & $1.11(1.02-1.21)$ \\
\hline NA30.int ${ }^{3}$ & $1.06(1.00-1.13)$ & $1.23(1.14-1.32)$ & $0.66(0.57-0.77)$ & $0.72(0.63-0.81)$ & $1.10(1.03-1.17)$ & $1.11(1.02-1.22)$ \\
\hline \multicolumn{7}{|l|}{ Adjusted estimates* } \\
\hline N.ext ${ }^{3}$ & $1.02(0.96-1.08)$ & $1.27(1.17-1.38)$ & $0.67(0.61-0.74)$ & $0.69(0.63-0.76)$ & $1.11(1.04-1.18)$ & $1.06(0.99-1.14)$ \\
\hline N.int ${ }^{3}$ & $1.04(0.97-1.11)$ & $1.27(1.17-1.39)$ & $0.66(0.59-0.74)$ & $0.69(0.62-0.76)$ & $1.09(1.03-1.16)$ & $1.07(0.98-1.16)$ \\
\hline NA62.ext ${ }^{3}$ & $1.04(0.97-1.11)$ & $1.34(1.23-1.46)$ & $0.62(0.54-0.72)$ & $0.65(0.58-0.74)$ & $1.10(1.02-1.18)$ & $1.07(0.98-1.16)$ \\
\hline NA30.int ${ }^{3}$ & $1.05(0.98-1.13)$ & $1.28(1.18-1.38)$ & $0.64(0.56-0.73)$ & $0.68(0.60-0.75)$ & $1.10(1.03-1.17)$ & $1.08(0.99-1.17)$ \\
\hline
\end{tabular}




\begin{tabular}{cccccc}
\hline SOL & TB & TSP & TST & WASO & SE \\
$\geq 30 \mathrm{~min}$ & $>9 \mathrm{hr}$ & $<6 \mathrm{hr}$ & $<6 \mathrm{hr}$ & $\geq 30 \mathrm{~min}$ & $<90$ \\
\hline OR (95\% CI) & OR (95\% CI) & OR (95\% CI) & OR (95\% CI) & OR (95\% CI) & OR (95\% CI)
\end{tabular}

\begin{tabular}{|c|c|c|c|c|c|}
\hline Harmonica $^{4}$ & & & 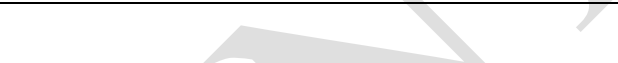 & & \\
\hline Crude estimates & $1.11(0.96-1.28)$ & $1.32(1.09-1.61)$ & $0.72(0.59-0.89) \quad 0.70(0.58-0.85)$ & $1.28(1.09-1.49)$ & $1.21(1.04-1.41)$ \\
\hline Adjusted estimates* & $1.07(0.94-1.22)$ & $1.36(1.14-1.61)$ & $0.65(0.53-0.80) \quad 0.61(0.51-0.73)$ & $1.26(1.08-1.48)$ & $1.20(1.02-1.41)$ \\
\hline
\end{tabular}

${ }^{*}$ Multivariate regression model adjusted on gender; age; marital status; educational qualifications; and body mass index (BMI)

${ }^{1}$ Per $10 \mathrm{dBA}$ increase

${ }^{2} \operatorname{Per} 10 \%$ increase

${ }^{3}$ Per 10 events increase

${ }^{4}$ Per 1 point increase

Bold values are statistically significant $(p<0.05)$ 
Supplementary table. Results of the linear regression models for the relationship between noise indicators and objective sleep parameters

\begin{tabular}{|c|c|c|c|c|c|}
\hline SOL & $\mathrm{TB}$ & TSP & TST & WASO & SE \\
\hline $\begin{array}{c}\text { Increase in second } \\
(95 \% \mathrm{CI})\end{array}$ & $\begin{array}{c}\text { Increase in second } \\
(95 \% \mathrm{CI})\end{array}$ & $\begin{array}{c}\text { Increase in second } \\
(95 \% \mathrm{CI})\end{array}$ & $\begin{array}{c}\text { Increase in second } \\
(95 \% \mathrm{CI})\end{array}$ & $\begin{array}{c}\text { Increase in second } \\
(95 \% \mathrm{CI})\end{array}$ & Increase (95\% CI) \\
\hline
\end{tabular}

\section{Integrated indicators}

\section{Crude estimates}

\section{LAeq.aero.ext ${ }^{1}$}

$$
-3.32(-17.0-10.4)
$$

101.8 (69.7 - 133.9)

116.5 (86.7 - 146.3)

102.6 (74.6 - 131.1)

14.5 (8.13 - 20.8)

$-0.03(-0.05--0.01)$

LAeq.aero.int ${ }^{1}$

12.1 (-8.66 - 32.9)

132.1 (82.9 - 181.3)

128.8 (82.6 - 174.8)

110.9 (67.1 - 154.7)

17.9 (8.09 - 27.7)

$-0.04(-0.08--0.01)$

\%Contrib.aero.ext ${ }^{2}$

$4.48(-1.81-10.8)$

29.5 (14.5 - 44.6)

26.8 (12.7 - 40.9)

$23.1(9.65$ - 36.4)

$3.40(0.39$ - 6.4)

$-0.01(-0.02-0.003)$

\%Contrib.aero.int ${ }^{2}$

$5.46(-5.77$ - 16.7)

$-2.70(-29.7-24.3)$

$-1.92(-27.3-23.5)$

$1.30(-22.6-25.2)$

$-6.08(-11.3--0.83)$

$0.01(-0.004-0.03)$

Adjusted estimates*

$\begin{array}{ll}\text { LAeq.aero.ext }^{1} & -4.35(-18.4-9.68) \\ \text { LAeq.aero.int }^{1} & 10.2(-11.3-31.6) \\ \text { \%Contrib.aero.ext }^{2} & 4.38(-2.04-10.8) \\ \text { \%Contrib.aero.int }^{2} & 4.64(-6.90-16.2)\end{array}$

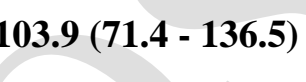

$120.8(90.9$ - 150.7)

107.1 (78.8 - 135.4)

14.2 (7.75 - 20.6)

$-0.03(-0.05--0.01)$

136.2 (86.2 - 186.3)

135.4 (89.1 - 181.6)

117.7 (74.0 - 161.7)

17.1 (7.15 - 27.1)

$30.3(15.2$ - 45.5)

28.2 (14.3 - 42.2)

24.6 (11.4 - 37.9)

$3.22(0.19$ - 6.25)

$-0.04(-0.08--0.005)$

$-3.93(-31.4-23.5)$

$-2.96(-28.6-22.7)$

$1.61(-22.5-25.7)$

$-6.88(-12.2--1.56)$

$-0.01(-0.02-0.004)$

$0.02(-0.003-0.03)$ 


\begin{tabular}{|c|c|c|c|c|c|}
\hline SOL & TB & TSP & TST & WASO & SE \\
\hline $\begin{array}{c}\text { Increase in second } \\
(95 \% \mathrm{CI})\end{array}$ & $\begin{array}{c}\text { Increase in second } \\
(95 \% \mathrm{CI})\end{array}$ & $\begin{array}{l}\text { Increase in second } \\
(95 \% \mathrm{CI})\end{array}$ & $\begin{array}{c}\text { Increase in second } \\
(95 \% \mathrm{CI})\end{array}$ & $\begin{array}{c}\text { Increase in second } \\
(95 \% \mathrm{CI})\end{array}$ & Increase (95\% CI) \\
\hline
\end{tabular}

Noise events indicators

Crude estimates

\begin{tabular}{|c|c|c|c|c|c|c|}
\hline N.ext ${ }^{3}$ & $-4.07(-9.64-1.49)$ & $82.9(70.6$ - 95.3) & $91.6(80.4-102.9)$ & 85.9 (75.2 - 96.6) & $8.04(5.45-10.6)$ & $-0.01(-0.02-0.003)$ \\
\hline N.int ${ }^{3}$ & $-2.83(-9.39-3.73)$ & $80.7(65.8$ - 95.5) & $86.9(73.3-100.6)$ & $80.4(67.4$ - 93.4) & $8.27(5.22-11.3)$ & $-0.01(-0.02-0.002)$ \\
\hline NA62.ext ${ }^{3}$ & $-4.34(-11.0-2.27)$ & $81.6(66.6$ - 96.5) & $87.1(73.3-100.9)$ & $81.2(68.0-94.3)$ & $7.78(4.69-10.9)$ & $-0.01(-0.02-0.004)$ \\
\hline NA30.int ${ }^{3}$ & $-2.08(-8.84-4.68)$ & $76.7(61.3-92.1)$ & $81.2(67.0-95.5)$ & $74.3(60.8$ - 87.9) & 8.18 (5.04 - 11.3) & $-0.01(-0.02-0.002)$ \\
\hline
\end{tabular}

Adjusted estimates*

\begin{tabular}{|c|c|c|c|c|c|c|}
\hline N.ext ${ }^{3}$ & $-4.99(-10.7-0.74)$ & $85.6(73.2-98.0)$ & $93.2(82.0-104.4)$ & $87.3(76.7$ - 97.9) & $7.80(5.16-10.4)$ & $-0.01(-0.01-0.004)$ \\
\hline N.int ${ }^{3}$ & $-3.64(-10.4-3.10)$ & $84.0(69.1-98.9)$ & 89.5 (76.1 - 103.0) & $82.9(70.1$ - 95.7) & $7.98(4.88-11.1)$ & $-0.01(-0.02-0.004)$ \\
\hline NA62.ext ${ }^{3}$ & $-5.10(-11.9-1.68)$ & $85.3(70.4-100.2)$ & $89.8(76.2$ - 103.4) & $83.7(70.7$ - 96.6) & $7.49(4.36$ - 10.6) & $-0.005(-0.02-0.01)$ \\
\hline NA30.int ${ }^{3}$ & $-2.93(-9.88-4.01)$ & $80.8(65.3-96.2)$ & $84.8(70.8$ - 98.9) & $77.8(64.4$ - 91.2) & $7.84(4.65-11.0)$ & $-0.01(-0.02-0.004)$ \\
\hline
\end{tabular}

\section{Harmonica}

Crude estimates

$60.3(-105.3-225.8) \quad 1153.2(759.5-1546.9) \quad 1115.0(750.6-1479.4) \quad 983.2(635.2-1331.2) \quad 147.6(69.9-225.4) \quad-0.32(-0.60--0.038)$

Adjusted estimates*

$46.1(-124.2-216.5) \quad 1229.1(831.0-1627.2) \quad 1210.9(849.8-1572.1) \quad 1075.0(731.1-1418.9) \quad 142.9(63.9-222.0)$

$-0.29(-0.57-\mathbf{- 0 . 0 0 5 )}$

* Multivariate regression model adjusted on gender; age; marital status; educational qualifications; and body mass index (BMI) 
${ }^{1}$ Per 10 dBA increase

${ }^{2}$ Per $10 \%$ increase

${ }^{3}$ Per 10 events increase

${ }^{4}$ Per 1 point increase

Bold values are statistically significant $(p<0.05)$ 